\title{
The Economic Life of the Aetas of Northern Philippines
}

\author{
Darin Jan C. Tindowen \\ University of Saint Louis, Philippines
}

\section{Introduction}

One of the unique characteristics of the Philippines is that it is a culturally diversed country. The United Nations Development Programme (2010) stated that there are around 14-17 million Indigenous Peoples (IP) that belong to 110 ethno-linguistic groups which are mainly concentrated in Northern Luzon (33\%) and in Mindanao (33\%), with some groups in the Visayas, Southern and Western Luzon, Palawan and in Sulu archipelago. Balilia (2013) defined Indigenous peoples as the descendants of the inhabitants of a country or a region who are present when people of different ethnic or cultural origins arrive and later become dominatedby more dominant Filipinos who migrated into the frontier areas in the $20^{\text {th }}$ century.

One of the popular Indigenous Peoples groups in the Philippines is the Negritos. CCP Encylopedia of Philippine Arts (1994) stressed that Negritos are the aborigines of the Philippines and considered to be the first migrants to the Philippines during the last glacial period about 25, 000 years ago when the sea level sank nearly 100 meters and land bridges appeared from Asian Mainland to the Palawan Island of the Philippines. Thomas (1994) stressed that Negritos are scattered throughout the Philippines, totaling an estimated 15,000 people. All are or were hunter gatherers. Furthermore, Ocampo and Ocampo (2014) described the Negritos as among the smallest people on earth. They are usually five feet tall, with black skin, dark kinky hair, round black eyes, and flat nose. Moreover, they are traditional people with culture belonging to the Old Stone Age. At present, the Negrito population is not a single "people group, but make up today 32 known distinct Negrito populations speaking 32 different languages or dialects (Headland, 2003).

The province of Cagayan, located in Northern Philippines, is a home to a great number of Negritos, or popularly known as the Aetas. History shows that the first inhabitants of the Cagayan Province were the Aetas. However, because of their nomadic character in seeking for their food and survival, they later moved to the 
uplands and some settled in the far flung areas, and most of them are found in forested hills on the remote parts of the municipal areas of Pamplona, Sta Ana, Gonzaga, and Penablanca. These groups of Aetas live in the hills and forests, and in the interior of the Sierra Madre Mountains.

A substantial number of studies suggest that Aetas still are nomadic in nature and practice traditional ways for survival such as hunting, fishing, and foraging (Salgado, 2002; Rashidi, 2000; Tamanut, 1996). Ocampo and Ocampo (2014) added that these tribal people do not give much importance to formal education since their primary concern is on their basic needs such as food. Hence, researches also concluded that these people are one of, if not the most deprived cultural minorities in the country (Headland, 1986; Torres, 2012).

In today's world, one of the bases for societal development is the use of the different technologies created by man. And as a result of technological advancement, many people shifted to the use of technological tools and instruments for food production to sustain their economic needs. Past researches also affirmed that one way for a society to attain development and progress is on the predominance of technology in agriculture, food production, and industries (Firouzi, 1990; Thomas, 2003; Moen, 1995). However, not all communities and groups can have an access to the different technologies created by man. And one of these groups is the Aetas of Northern Philippines. Agta community in Northern Philippines, specifically in Agugaddan, Penablanca, Cagayan Province is a small village located on the foothills of Sierra Madre mountain ranges near the Callao Caves, a famous tourist site in the area, and Pinacanauan River. This tribal group is originally from the far flung areas in the municipality of Gattaran, Cagayan. But because of their need to survive to their everyday living, some of them migrated to Peñablanca, Cagayan in the mid-1980s in search for better opportunities and ways of living. However, researches also revealed that because of their constant interactions with other ethnic groups, their ways of living, especially on their economic survival is now starting to change (Ocampo and Ocampo, 2014; Jacob, 1997). Hence, this study was conducted to determine the economic activities and seasonal activities for survival of this ethnic group.

\section{Literature Review}

\section{Indigenous Peoples in the Philippines}

The Indigenous People Right Act (IPRA 1997) defined Indigenous Peoples as a group of people or homogenous societies identified by self-ascription and 
ascription by others, who have continuously lived as organized community on communally bounded and defined territory, and who have, under claims of ownership since time immemorial, occupied, possessed and utilized such territories, sharing common bonds of language, customs, traditions and other distinctive cultural traits, or who have, through resistance to political, social and cultural inroads of colonization, non-indigenous religions and cultures, became historically differentiated from the majority of Filipinos. Moreover, they shall likewise include peoples who are regarded as indigenous on account of their descent from the populations which inhabited the country, at the time of conquest or colonization, or at the time of inroads of non-indigenous religions and cultures, or the establishment of present state boundaries, who retain some or all of their own social, economic, cultural and political institutions, but who may have been displaced from their traditional domains or who may have resettled outside their ancestral domains.

De Vera (2007) stressed that Indigenous Peoples represent nearly $14 \%$ of the country's population. They are among the poorest and the most disadvantaged social group in the country. Illiteracy, unemployment and incidence of poverty are much higher among them than the rest of the population. IP settlements are remote, without access to basic services, and are characterized by a high incidence of morbidity, mortality and malnutrition. In addition, Gaillard (2006) mentioned thatindigenous peoples are commonly defined as the descendants of the inhabitants of a country or region who are present when people of different ethnic or cultural origins arrived and later become dominant through settlement or occupation of some means.

Meanwhile, the Asian Development Bank (2002) defined Indigenous People as those with a social or cultural identity distinct from the dominant or mainstream society, which makes them vulnerable to being disadvantaged in the processes of development.

The U.N. Sub-Commission on the Prevention of Discrimination and Protection of Minorities (1971) defined Indigenous people as indigenous communities, peoples, and nations are those which, having a historical continuity with pre-invasion and pre-colonial societies that developed in their territories, considered themselves distinct from other sectors of the societies now prevailing in those territories, or parts of them. They form at present non-dominant sectors of society and are determined to preserve, develop and transmit to future generations their ancestral territories, and their ethnic identity, as the basis for their continued existence as peoples in accordance with their own cultural patterns, social institutions and legal systems. 
The International Labor Organization (ILO) (1996) said that Indigenous people are descendants of the aboriginal population living in a given country at the time of settlement or conquest by some of the ancestors of the non-indigenous groups in whose hands political and economic power at present lies. In general, those descendants tend to live more in conformity with the social, economic and cultural institutions which existed before colonization or conquest than with the culture of the nation to which they belong; they do not fully share in national economy and culture owing to barriers of language, customs, creed, prejudice, and often to an out-of date and unjust system of worker-employer relationships and other social and political factors.

The organization, Tunay na Alyansang Bayan Alay sa Katutubo or TABAK (1990) stressed that Indigenous peoples' communities can be found in the interiors of Luzon, Mindanao, and some islands of Visayas. They either withdrew to the hinterlands in the face of colonization or they stood their ground successfully and have maintained a close link to their ancestral past. These communities comprise a diverse collection of more than forty ethno-linguistic groups, each with a distinct language and culture.

Molintas (2004) said that the primary struggle of Indigenous People today is on land ownership. Depriving indigenous peoples of their ancestral lands will mean the complete loss of their identity as distinct peoples. Thus, no less than the question of survival is now at stake for the indigenous peoples in the Philippines. The remaining links with their ancestral past are being destroyed forever. Institute for Autonomy and Governance (2007) also added that the recognition and protection of indigenous peoples' rights is one struggle that has been carried out for many years now such as the IPs of the Autonomous Region for Muslim Mindanao (ARMM) and of the Cordillera Administrative Region (CAR).

\section{The Aetas of the Philippines}

Encyclopedia of Philippines Arts (1994) enumerated different names of Aetas in the Philippines such as Ayta, Agta, Atta, Ati and Ita. These names are usually based on their geographical location, history, or relationship with other people. Spanish records show that they were called Negritos or "Little Black One" by the Spanish colonizers. A term they coined from the word Negro meaning dark skinned. In the world of ethnographic literature, at present, they are more popularly known as Negrito Pygmy. Approximately, the Negrito Population throughout the Archipelago is roughly 90,000 and divided into 25 ethno linguistic groups 
dispersed in bands from Luzon to Mindanao. The most numerous are those found in the islands of Luzon.

Molintas (2004) said that the Aetas are considered as one of the major groups of Indigenous Peoples in the Philippines. Agta and Aeta/Negrito are short, darkskinned and kinky-haired people who are considered to be the earliest inhabitants of the Philippines. Aside from having been perpetually pushed into the hinterlands of Central Luzon, mainly in the provinces of Zambales, Bataan and Pampanga, and in other parts of the country, they also suffer from racial discrimination. With a population of about 160,000 , they are the most widely distributed among indigenous peoples.

Nives, Katja, and Vesna (2012) identified Aetas as included among the so-called negritos. The Agtas are small in stature (women are approximately $140 \mathrm{~cm}$ tall), and they have a decidedly dark complexion and curly hair. In the 16th century, when the Philippines was conquered by the Spanish, they moved from the lowlands into the mountains. On account of their peacefulness, they moved away from the conquerors and settled in the slopes of mountains.

Ocampo and Ocampo (2014) described the Aetas as the smallest people on earth. However, they are among the world's best archers and herbalists. The bow and arrow carrying pygmies or Aetas were considered as the earliest inhabitants of the mountain regions of Northern Luzon.

Earley (1994) mentioned that Aetas live in a close-knit community; their way of life is characterized by their care and concern for the entire community, and is reflected in their mutual support and solidarity. They help each other in all areas of life: they build houses together, cultivate the land, they learn together, and frequently, they also cook together.

Majority of the researches on Aetas in the Philippines revealed that the Aetas still rely on the natural resources as their major source for their economic activity such as foraging, hunting wild animals, farming, and fishing (Ocampo and Ocampo, 2015; Malicsi, 1982; Gloria, 1997; Simon, 1988-1989; Headland, 2003; Tamanut, 1996).

The result of the study of Nives, Katja, and Vesna (2012) revealed that the Aetas of Zambales, Philippines are known for their particular method of farming; they grow sweet potatoes, bananas and vegetables. They are also known for their forms of alternative medicine. Meanwhile, Shimuzu (1989) stated that the Aetas of Luzon are nomadic people. Their social activities revolve around hunting of birds, frogs, and other animals, and gathering of fruits, insects, and mushrooms (Shimizu 1989). 
According to Andrada (2007), the Aetas are an erstwhile nomadic tribe in northern Cordillera, who have learned to build houses from indigenous materials.. Part of their cultural practices are now gone. They still depend, however, on the dipterocarp forest for survival. They still rely on its timber and on timber resources for food, clothing, medicines, and shelter, cleaning materials, fiber utensils, handicraft, hunting tools and ritual paraphernalia. On lean months, they turn to the dipterocarp forest of Apayao, Province to search for wild food plants and hunt for wild animals.

\section{Methods}

\section{Research Design:}

This study employed a qualitative type of research utilizing ethnographic method.

\section{Informants:}

The informants of this study were the 25 Aeta families located in Agugaddan, Peñablanca, Cagayan, Northern Philippines. Purposive sampling through site selection and networking approaches was utilized to determine the total number of participants of the study. Of the 80 informants, $60 \%$ were male. The average age of the informants is 35.5, with an average 3-5 number of children. Moreover, $90 \%$ of the informants did not attend any formal schooling.

\section{Instruments and Procedures}

Interview and observation in the community for almost one year and community immersion for almost two months were used as the main instruments to gather the needed data of the study. Ilokano, Itawes, and Filipino were used as media of expression during the interview since most of the informants were using these kinds of languages as their means of communication. However, the researcher established first a good rapport with the Aetas by participating in their daily activities in order to gain trust and so not to arouse any suspicion on the part of the Aetas. The researcher also employed the technique of field diary, the use of camera for documentation, and recorder to record the data needed in the study. To validate the data gathered from the respondents, the researcher verified these said data with the key informants and elders in the community. Ethical consideration was also practiced by the researcher such as keeping the confidentiality of the respondents, key informants, and the elders. 


\section{Results and Discussions}

\section{A. Economic Activities of the Agtas \\ a. Foraging}

Foraging is one of the oldest occupations of the Aetas where they gather edible plants, wild orchids, and ornamentals directly from the wild (Ocampo\&Ocampo, 2014). Foraging is one of the major activities of the Aetas of Northern Philippines in order for them to survive in their daily needs. The Aetas gather edible plants, wild orchid, ornamentals, fruits, tree resins, copal honey, and fire woods in the forest near their community.

Products derived from foraging are being sold by the Aetas in the Public Market; in the vicinity of Callao Cave, a famous tourist attraction in the Cagayan Province, and in their own homes. Edible plants and wild orchids and ornamental plants cost $\mathrm{PhP} 25.00$ (\$0.50) per piece, while fire woods are being sold at around PhP 50.00 $(\$ 1.00)$ per bundle. And, the fruits that they gathered are used for their own consumption.

\section{b. Livestock and Poultry Production}

The Aetas of Northern Philippineswere also into livestock and poultry production. The income that they earned from foraging, paid labor, and upland farming was used to sustain their daily needs. More importantly, some portion of their income was used to buy chickens, pigs, and ducks for them to take care for their personal future consumption. Most Aeta women were the one responsible in taking care of the animals.

\section{c. Farming and Agriculture}

The Aetas were also engaged in farming near their community where they need to clear a small area for planting crops to sustain their needs. The usual crops being planted by the Agtas are Rice, Corn, Bananas, Cassavas, and other root crops. The crops that they produced are used for their daily consumptions. Rice, boiled cassavas and bananas are usually their daily starch food. And sometimes, root crops and boiled cassavas are their substitute in the absence of rice. Also, Aeta women usually mix cassavas and rice in order to maximize the supply of rice they have in the family. It is important to note that rice is considered as the major daily starch food of the Filipinos including the Aetas. Throughout the $20^{\text {th }}$ century, Aeta groups throughout the Philippines were found to acquire most of their carbohydrate foods from lowland farmers by trade through the exchange of forest products such as wild meat, medicinal plants, and orchids (Headland, 1986; Shebasta, 1980; and 
Molintas, 2004). However, the result of the study is different from the results of previous literatures and settings. Today, the aetas of the Northern Philippines have a small portion of rice field to cultivate. Also, instead of trade, the aetas are being hired by rice field owners to render farm services of which they are paid with a sack of rice in return.

Farming is both an activity of a man and a woman in the Aeta community. Usually, men are the ones preparing the land, while women are the one planting, cultivating, and harvesting the crops.

\section{d. Making and Selling Hard Brooms}

One of the dominant plants in the areais the coconut tree from which the Aetas usually generate edible food and fire wood. And as a result, making and selling brooms became one of the occupations of the Aetas, especially for the women, since most of the women are left in their homes taking care of their children and doing the household chores. Also, this is to help their husbands in raising money to sustain their needs. The price of the broom would be around Php 25.00 (\$0.50) per piece.

e. Recipients of the Pantawid Pampamilya Pilipino Program (4Ps) of the Government

Pantawid Pampamilya Pilipino Program (4Ps) is a poverty reduction and social development strategy of the national government that provides conditional cash grants to extremely poor households to improve their health, nutrition and education particularly of children aged $0-14$. The program is currently being implemented by the Department of Social Welfare and Development (Montilla, Delavin, Villanueva, \& Turco, 2015). Guia (2011) stressed that the said program is widely implemented among Indigenous Peoples (IPs) and the Aeta community is one of the recipient communities of the said program. However, not all Aeta families are recipient of the 4Ps of the government. Result of the interview revealed that only those families with a minimum number of 3 children are the beneficiaries of the program wherein each family receives Php 1,400.00 per month. Also, the result of the interview revealed that the money they received from the said program was used to pay their electric bills and for the education of their children. This implies that the Agta community is already immersed with the culture and way of living of the lowlands. 


\section{B. Seasonal Activities for Survival of the Aetas}

a. Fishing

Fishing is one of the seasonal economic activities of the Aetas. They usually do fishing during sunny seasons in Pinacanuan River and in Buyag river where water is clear. They are famous in catching Igat or black eel. The Aetas wore only their underwear and goggles when fishing with the use of batawat or eel gear, an improvised arrow. Usually, they could catch an average number of 5 eels every day during sunny seasons. And they preserved the eel with salt so that the day after, Aeta women would sell the eel in the Centro of Peñablanca. The price of the eel they sell is $\mathrm{PhP} 500.00$ (\$10.00) per kilo. The income that they derived from selling the eels is used to buy rice which they divide among themselves in the community. Also, giant tilapias are dominant in the place.

\section{b. Paid Labor}

One of the dominant transformations of the Aetas is on social interaction and relationship. And as a result, the Aetas learned to work in the farm in exchange of daily wages and rice. The Aeta men are the ones going to the farm and do plowing, planting, weeding, harvesting, and hauling. They are given $\mathrm{PhP} 150.00$ (\$3.00) per day as their wage. Also, in most cases, they are given one sack of milled rice instead of cash as their wage for the whole duration of labor. This activity is favorable for the Aetas because they do not have enough land to cultivate and they do not have stable job to earn for living. The results also imply a well-established symbiotic relationship between Aeta communities and lowland farmers. The results reveal a unique trading relationship between Aeta families and lowland trading partners.

c. Being Hired by Government and Private Sectors to present their Cultural Dance or Talip

Contrary to the results of some researches that Aetas are isolating themselves from the lowlanders, the Aetas of Northern Luzon learned to immerse themselves to the mainstream societies. And one of these activities is that they are being hired by some Government and Private sectors to present their Talip, their indigenous dance, during festive events and cultural activities. Usually, average of ten Aetas is participating on the said activity and in return, they are being paid for their participation. Result of the interview revealed that the costumes that they are using are actually being sponsored by a private organization. The money that they derived from dancing is actually being divided among the Aeta families. This 
suggests that unity and sense of belongingness in a community still exist which for this ethnic group is of great value.

\section{d. Tour Guiding in Callao Cave}

Callao Cave is one of the most popular caves in the Philippines being visited by local and international tourists (lakwatsero.net 2013). It is located in Barangays Parabba and Quibal of Peñablanca, Cagayan, Northern Philippines. The said tourist attraction gives also the Aetas an opportunity to earn and to survive for their living. Some of the Aetas, especially those who are in their teenage and early adulthood years are working in the Callao cave as tour guides. Also, results of the interview revealed that the income of the two Aeta tour guides is used to sustain their education and to help their families sustain their economic needs.

e. Recipient of Different Outreach Activities conducted by the NonGovernment Organizations and Schools and Universities

The Aetas of Northern Philippines are fortunate in terms of extension and outreach activities because most of the Higher Education Institutions and Non-Government Organizations in Northern Philippines have an extension and outreach programs on the said tribal community. According to the Aeta informants, most of the activities being conducted in their community are literacy and information drive, feeding program, clothes and food donations, and Catechetical formation program. Also, there is a great number of organizations helping the community every December as part of their mission and extension drive.

It is important to note that most of their seasonal activities are results of their interaction and immersion with other ethnic groups and with the lowlands. Their acquaintances with other groups bring them opportunities to undertake various activities such as paid labor and fishing. Moreover, the paper also revealed that the Aeta's perspectives with regard to the isolation of their community have gradually changed. The Aeta community of Northern Philippines already opened its doors to the mainstream communities in order to survive. The community members already have manifested this through their social interaction and involvement by presenting their talip or their community dance and also their positive interaction as beneficiaries of outreach activities and extension projects of Non-Government Organizations as well as schools and universities. 


\section{Conclusion:}

Despite rapid technological advancement, the Aetas of Northern Philippines are able to cope with this challenge. Foraging, livestock and poultry production, farming and agriculture, making and selling hard brooms, and being recipients of the Pantawid Pampamilya Pilipino Program of the government are the major economic activities of the said group.

Meanwhile, fishing, paid labor, being hired by Government and Private Sectors to present their Cultural Dance or Talip, tour guiding in the Callao cave, and being a recipient of different outreach activities conducted by the Non-Government Organizations as well as Schools and Universities in Tuguegarao City and Peñablanca, Cagayan are the coping and seasonal activities of the Aetas that help them sustain their basic needs. Their social interaction and immersion with the lowlands gave them opportunities to do alternative activities to sustain their economic life.

The present paper shed lights to existing literatures on the current practices and activities of Indigenous Peoples Groups in the Philippines. Possible extension of this study is to look into the effects and impacts of their economic activities on their socio-economic lives.

\section{References and notes:}

1. Asian Development Bank (2002). Indigenous peoples/ethnic minorities and poverty reduction Philippines. Manila: ADB Publication

2. Balilia, V., McHenry, J.A. (2013). Indigenous aeta magbukún self-identity, sociopolitical structures, and self-determination at the local level in the Philippines.Journal of Anthropology, 2013, 1-6.

3. CCP Encyclopedia of Philippines Arts (1994).Retrieved November 7, 2015 from http://www.aetachildren.org/index.php?option=com_content $\&$ view $=$ article $\& i d=10 \&$ Itemid=6.

4. David, M.E.(2011). Aeta mag-achi's cultural history, concept of time, and territoriality: its implication to education. International Proceedings of Economics Development and Research, 2(2), 113-116.

5. De Leon, A. M., Reyes, R.G., \&Dela Cruz, T.E. (2012) An ethnomycological survey of macrofungi utilized by aeta communities in Central Luzon, Philippines.Mycosphere. 3, (2), 251-259.

6. De Vera, D. (2007). Indigenous peoples in the Philippines. Presented at the RNIP Regional Assembly. Hanoi, Vietnam.

7. Doma, C. (2002). The impact of resettlement to malasaaetas and its implications for future community development programs.Unitas, 75(1), 115-132. 
8. Early, J. D. (1994).Population dynamics of a Philippine rain forest people: theSan Ildefonsoagta. Gainesville: University Press of Florida Press.

9. Gaillard,J.C. (2006) Traditional societies in the face of natural hazards: the $1991 \mathrm{Mt}$. Pinatubo eruption and the aetas of the Philippines. International Journal of Mass Emergencies and Disasters, 24,5-43.

10. Headland, T. N. (1986) Why foragers do not become farmers: a historical study of a changing ecosystem and its effect on a negrito hunter-gatherer group in the Philippines (agta, cultural ecology, homicide, competitive exclusion principle, time allocation). Published Doctoral Dissertation. University of Hawii.

11. Headland, T. N. (2003). Thirty endangered languages in the Philippines. Work papers of the Summer Institute of Linguistics, University of North Dakota, vol. 47. Retrieved August 3, 2016 at https://arts-sciences.und.edusummer-institute-oflinguistics/work-papers/2003/cfm.

12. Institute for Autonomy and Governance (2011). The struggle continues: uphold the rights of indigenous peoples. Notre Dame University.Cotabato City: Philippines.

13. Jacob, T. I. (1977) Old agein the ruralPhilippines.Published Doctoral Dissertation.Western Michigan University.

14. Maceda, M. N. (1981). The Mamanuas of Northern Mindanao.The Philippine Journal of Science, 82, 24-30.

15. Magulod, G. C. (2015). Survival mechanisms of the aggays of lasam, Cagayan.Unpublished Institutional Research.Cagayan State University Lasam.

16. Malicsi, J. (1982). On the Sambalayta concept of beauty. Readings in Philippine Socio-Linguistics, 1, 75-80.

17. Molintas, J.M. (2004). The Philippine indigenous peoples' struggle for land and life: challenging legal texts. Arizona Journal of International and Comparative Law, 21(1).

18. Montilla, M.M, Delavin, E. A., Villanueva, R. M. \& Turco, R. A. (2015). Pantawid pamilyang Pilipino program (4Ps): Assistance to pupil's education. Asia Pacific Journal of Education, Arts, and Sciences, 2(3), 1-5.

19. Moralista, R. B. \&Delariarte, G. C. (2014).The educated citizen: cultural and gender capital in the schooling of aetas' children in the municipality of Janiuay. Asia Pacific Journal of Education, Arts, and Sciences, 1(1), 1-6.

20. National Commission on Indigenous Peoples (1998).Indigenous peoples' rights acts implementing rules and regulations. Quezon City: NCIP.

21. Nives L. ,Lithenvalner K., \& Podgornik V. (2012).The non-formal education and migration of the aeta, an indigenous tribe in the Philippines. Anthropological Notebook, 18(3), 25-40.

22. Ocampo, R. \& Ocampo, R. (2014).The economic life of the negritos of Luna, Apayao. Asia Pacific Journal of Multidisciplinary Research, 2(1), 139-142.

23. Runoko, R. (2000). Black people in the Philippines. Retrieved November 7, 2015 from http://www.cwo.com/

24. Shebasta, P. (1980). The Pinatubo negritos- their useful plants and materials culture.The Philippine Journal of Science. 81, 173-414.

25. Shimizu, H. (1989). Pinatubo aytas: continuity and change. Quezon City; Ateneo De Manila University Press

26. Simon, Samuel E. (1988-1989). The community life of the Dumagats of Palanan, Isabela. Journal of Northern Luzon, 19, (1-2), 1-5

27. TABAK (1990).Struggle against development aggression: tribal Filipinos and ancestral domains.Philippines. 
28. Tamanut, A. (1996). Cultural practices and beliefs of the agtas of the coastal areas of isabela: its implication to socio-economic life and education. Unpublished Master's Thesis.Northeastern College.

\title{
Summary
}

\section{The Economic Life of the Aetas of Northern Philippines}

\author{
Darin Jan C. Tindowen \\ University of Saint Louis, Philippines
}

In today's world, one of the bases of economic development is the presence of technology. However, not all communities and groups can have an access to the different technologies created by man. And one of these groups is the Aetas of Northern Philippines. This study was conducted to determine the different economic activities, and seasonal activities for survival of the Aetas. The participants of the study were the 25 Aeta families of a rural community in Northern Philippines. In-depth interview, observation, and community immersion were the instruments used by the researcher. Moreover, key informants and the elders were identified to validate the data gathered by the researcher.

Results showed that the economic activities of the Aeta community are foraging, livestock and poultry production, making and selling hard brooms, farming and agriculture, and some families are recipients of the Pantawid Pampamilya Program of the Government.

Moreover, seasonal activities for survival included fishing, paid labor, tour guiding inside the Callao cave, being recipients of the different outreach and extension activities conducted by Non-Government organizations and schools and universities located in Tuguegarao City and in Peñablanca, Cagayan, Philippines; and some of them were compensated during cultural festivals and other festive events by presenting the Talip, the Aetas community and indigenous dance.

Keywords: Aeta community, Northern Philippines, Economic Activities, Seasonal Activities,cultural festivals. 